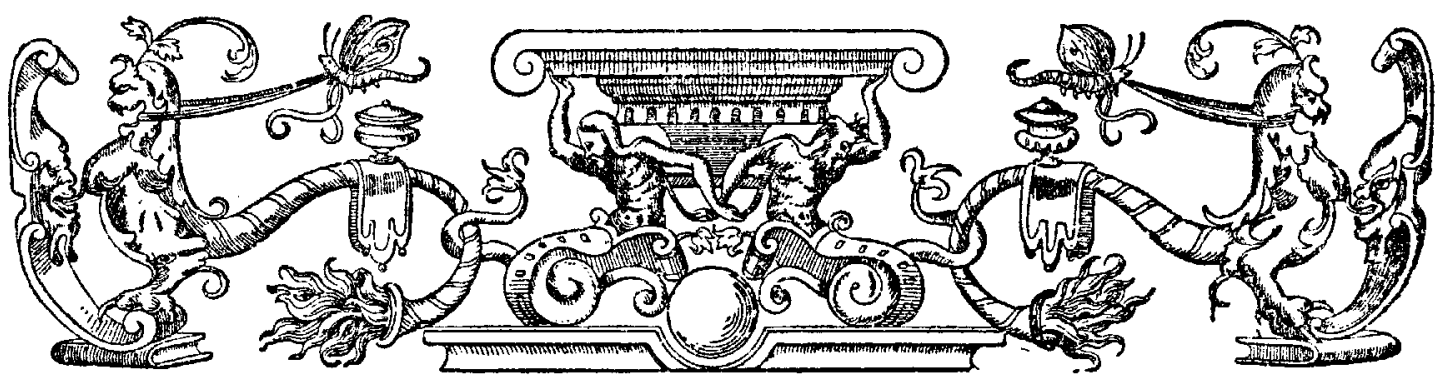

R E M B R A N D T I A N A

DOOR

A. B R E D I U S.

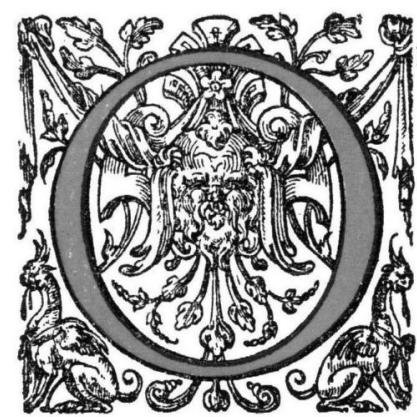

P 't onverwachtst zijn dezer dagen weer twee documenten over REMBRANDT aan het licht gekomen, waarvan vooral het eene van veel belang is en wêer een nieuwen blik doet slaan op het ons zoo boeiende leven van den Meester. De gelukkige vinder, Jhr. D. Rutgers van Rozenburg, zond ze mij toe, met de toestemming ze hier te publiceeren.

Wij weten in hoe netelige omstandigheden REMBRANDT zich in het jaar 1656 bevond. Hij had jaren geleden een huis gekocht maar nog altijd niet betaald, overal geld geleend, en zijne schuldeischers werden steeds ongeduldiger. Steeds vroeg men: Waar heeft RemBrandT dan toch zijn geld gelaten? Zijne Saskia was rijk; hij werd voor zijn tijd beter betaald dan eenig ander hollandsch schilder, men weet niet, dat hij een verkwister was, alleen - en dit werd algemeen als de oorzaak van zijn financieelen ondergang aangenomen - zijn groote passie om zich met schoone dingen te omringen kostte hem veel geld. Op veilingen betaalde hij record-prijzen, en zijn huis was een klein Museum geworden.

Maar nu blijkt het, dat er toch andere redenen bij kwamen. REMBRANDT 
vertelt dit zelf, en daarom kunnen wij het wel gelooven. Hij was werkelijk een beetje "Coopman" er bij, zooals hij al eens, vroeg, in een te Rotterdam verleden acte, genoemd wordt. Hij zegt, dat hij in dien ongelukkigen toestand geraakt is door "verliesen in de negotie, alsmede schaden en de verliesen bij der Zee".

In dien tijd van koortsachtig jagen naar rijkdom, van bloeienden handel en bedrijf, deed iedereen zoowat mede. Ik vind toch dat de kundige medicus, de deftige burgemeester NICOLAAS TULP, evengoed zijne schepen bevrachtte als de gewone kooplieden dit plachten te doen. Hoogstwaarschijnlijk is REMBRANDT door kennissen medegesleept om "mede te doen" en wel met het treurige gevolg, dat hij "brieven van cessie" moest aanvragen.

De ,negotie" kan doelen op zijn handel in schilderijen, maar waarschijnlijk eer op andere handelszaken; REMBRANDT heeft denkelijk ongelukkig gespeculeerd. Het tweede document, ook onbekend tot nog toe, is de aanvrage van den voogd van REMBRANDT's kleindochter TITIA, om den boedel van den schilder te mogen aanvaarden onder beneficie van Inventaris. Hier volgen de twee stukken.

Aen de hooghe Overicheyt.

Geeft reverentelyck te kennen REMBRANDT VAN RIJN woonende tot Amsterdam, dat hij suppliant door verliesen geleden in de negotie, alsmede schaden ende verliesen by der $Z$ ee in soodanigen ongelegentheyt is geraeckt, dat hem niet mogelyck is syne crediteuren te konnen voldoen, ende alsoo deselve syne Crediteuren, met naemen d'Heer Burgem. Cornelis Witsen, IsaACQ Van Hersbeecl, Mr. Daniel Francen, Gerbrant Ornia, Hiskia van Vuylenburch, GERRIT DIRCXS, GERRIT BOELISSEN ende andere wel behoorden daerop reguardt te nemen, Is het echter sulcx, dat hij werdt gedreijcht van deselve te sullen werden overvallen, oirsaecke waeromme den suppliant genootsaeckt is sich te adresseren aen UE: $\mathrm{H}$ : Overicheyt, oytmoedelick versouckende brieven van Cessie, met committimus aen den Gerechte van Amsterdam, d'welck doende etc.

$$
\begin{gathered}
\text { (w.g.) N. GeltSACK. } \\
1656 .
\end{gathered}
$$

In margine staat: Fiat advys aen Burgemen ende Regeerders van Amsterdam. Gedaen in den Hoogen Rade in Hollt desen I4 July 1656. (w.g.) ImaN CAU. Lager :

Gesien rescriptie fiat mandt van cessie met committimus aen den Gerechte van Amsterdam. Gedaen in den Hoogen Rade in Hollt desen 8 Augustii 1656. (w.g.) IMAN CAU. ${ }^{1}$ ).

1) Requesten Hooge Raad. Portef. No. 60. 
Aen den Ed. Hoogen Raede in Hollandt.

Geeft reventelijck te kennen Franchois vaN BYLERT, woonende te Amsterdam, als by Weesmeesteren derselver stadt gestelde voocht over het kint van TITUS VAN RIJN, die een soone was van REMBRANDT VAN RIJN, dat denselven REMBRANDT VAN RIJN, in syn leven schilder aldaer, nu onlangs verleden binnen de voorsz. stadt deser werelt is comen te overlyden, achterlatende tot syn erffgenaem het kint van syn overleden soon TITUS VAN RIJN, dan alsoo den suppliant in de voorsz. qualité beducht is, dat deselffs boedel met eenige onbekende schulden soude moge sijn geïnvolveert, sulcx de simpele aenvaerdinge van dien hem in tijden ende wijlen soude mogen schadelijck syn, vont den suppliant in de gemelte qualtiteyt niet geraden denselven boedel anders te aenvaerden dan onder benefitie van Inventaris.

Versouckende derhalven Uwer Ed: Mo: Heeren brieven van beneficie van Inventaris met de clausule van relief(en) committimus aen den Gerechte der voorsz stadt in communy forma: Dit doende etc.

(w.g.) T. J. van Nassau.

\section{Boven stond:}

Fiat opene brieven van beneficie van Inventaris met de clausule van relieff ende committimus aen de Gerechte der Stadt Amsterdam.

Gedaen in den Hoogen Raede in Hollant den 28 October 1669. ${ }^{1}$ )

REMBRANDT schilderde in 1642 voor $f$ 500.- den Heer ABRAHAM WilMERDONCX en zijn huisvrouw. Dit blijkt uit een in Oud-Holland III medegedeelde Acte, die door Dr. Hofstede de Groot werd overgenomen met de opmerking: "aus dieser Akte geht nicht deutlich hervor, „ob es sich um zwei Bildnisse oder um ein Doppelporträt handelte". Dat het laatste toch voor de hand lag, meen $\mathrm{ik}$ te mogen afleiden uit de uitdrukking: de somme van tsestigh gulden voor 't doek en lijst. Een nadere bevestiging van dit vermoeden vond ik in den Inventaris van wijlen Juffr ANNA WILMERDONCX, bejaarde dogter, gewoond hebbende en overleden binnen deese stadt (Amsterdam) in de maand Augustii 1721.

$$
\text { Op de Zaal. }
$$

Een groote schilderije van REMBRANDT . . . . . . . . f 60.-

$\mathrm{Nu}$ kàn natuurlijk dit een geheel andere schilderij van REMBRANDT zijn; doch in verband met het andere document is het vermoeden gewettigd, dat dit „groote schilderij" op één doek de portretten van Mejuffrouw WiLmerdoncx' 
ouders bevatte. Een dergelijk portretstuk van 1642 van REMBRANDT is voorloopig onbekend. 1)

De geheele familie WILMERDONCX bezat trouwens nog werk van REMBRANDT. In April I7I8 werd de Inventaris beschreven van CATHARINA WilmerDONCX. Daar waren:

een boerenbinnenhuis van OsTADE, getaxt op . . . . . . f $f$ 16.een groot stuk: de Rentmeester van? . . . . . . . 20.een morgenstond van Sagtleven . . . . . . . . . I5.een do van do . . . . . . . . . . 15.twee boerekermissen van Droochsloot . . . . . . . 24.een Bacchus van Goltzius . . . . . . . . . . . 16.het Doopen van Kristus van Goltzlus . . . . . . . 20.een groot stuk van REMBRANDT . . . . . . . . . 200.-2) Is dit soms hetzelfde stuk wat wij zooeven bij ANNA WILMERDONCX aantroffen?

En wie is de tweede Juffr Anna Wilmerdoncx 7 Mey I695 de Wede van CORNELIS WILS genoemd, die onder meer een lantschapje van WIJNANTS bezat, dat op $f \mathrm{I} 2$ geschat werd en

een oude man van REMBRANDT, op . . . . tien stuivers getaxeerd! ${ }^{3}$ )

27 Maart 1693 worden in den boedel van ADRIAAN WITSEN een lantschap van MOUCHERoN op $f$ IO.- geschat, zes teeckeninghen van REMBRANDT op één gulden en tien stuivers ! ${ }^{3}$ )

In de groote verzameling schilderijen die Lodewijk van ERPECum te Amsterdam bezat, en waarvan 4 Nov. I 692 voor Not. RINDT een Inventaris werd opgemaakt, bevinden zich

twee landschapjes van REMBRANDT.

nog een wintertje van REMBRANDT.

(waarschijnlijk het beroemde stukje te Cassel).

een kinderconterfeitsel van REMBRANDT.

een trony van REMBRANDT.

Onder de curiosa dezer verzameling behoort de Godin Ceres met een naekt kintie van EMANUEL DE WIT.

en vele portretten door LIEveNS, Vader en Zoon.

5 Nov. I708. Inventaris Mr. JACOB Fransz, Chirurgyn, tot Amsterdam. I. een Blommendael's bleekie met Haerlem int verschiet door vaN KESSEL. 2. een fruytschael door VAN STREEK (Juriaen).

1) Prot. Not. P. van Aken, Amsterdam.

2) Prot. Not. PAddenburg, Amsterdam.

3) $n$ "STEEman, Amsterdam. 
3. een duyfie door dito.

8. een biddent begyntie door J. MolenaER.

I I. Scheepie door ZeEman.

I2. Cornelis de Wit door vaN StREeK.

13. Jan de Wit door van StReEK.

15. een Out mans tronitie door Rembrant.

I7. een man, lantaren en kan door . . . CAMPhuiJSEN (denkelijk GoverT).

31. een Waterveruwtie door MARgreta de HeEr.

40. een Waterveruwtie door REMBRANTS.

49. Haerlemmer bleekie door K. Molenaer. ')

1) Prot, Not. J. BAcker, Amsterdam.

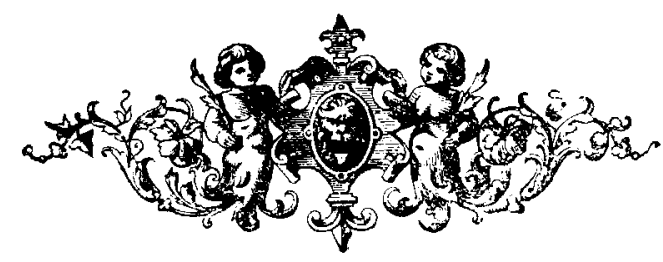

